\title{
HLA Antigens in Migraine
}

Brian P. O'Neill, M.D., Janet J. Kapur, B.A., M. T. (ASCP) and Armin E. Good, M.D.

Departments of Neurology (Dr. O'Neill) and Internal Medicine (Dr. Good), University of Michigan Medical Center; the Neurology (Dr. O'Neill and Rheumatology (Dr. Good) Services, Ann Arbor VA Hospital; and the Histocompatibility Research Laboratory (Ms. Kapur), Ann Arbor VA Hospital, Ann Arbor, MI.

Funded through the Medical Research Service, VA Hospital, Ann Arbor, MI.

Reprint requests to: B. P. O'Neill, M.D., Department of Neurology, Mayo Clinic, Rochester, MN 55901.

Accepted for Publication: December 22, 1978

SYNOPSIS

Fifty consecutive patients with migraine headaches were evaluated for the presence of 10 HLA-A and 14 HLA-B antigens by means of the microlymphocytotoxicity assay. Comparisons were made between classical and common migraine, and between patients with and without a family history of migraine. All groups of patients showed an association with B8 and B27, which failed to reach clinical significance. This data suggests that the multifactorial inheritance postulated for migraine probably does not require the participation of the HLA-A or B locus of the major histocompatibility complex.

(Headache 19:71-73, 1979)

\section{INTRODUCTION}

The extreme polymorphism of the major histocompatibility complex (MHC) makes it a suitable marker for investigating diseases where hereditary transmission is suspected, particularly where immune system abnormalities are prominent. ${ }^{1}$ Since both immune mechanisms ${ }^{2}$ and multifactorial inheritance ${ }^{3}$ have been proposed in migraine, we have examined whether association exists between any HLA antigens of the MHC and migraine.

\section{PATIENTS AND METHODS}

Patients: Fifty unrelated migraine patients were randomly selected for study. All patients had been referred to the Neurology Clinics of either the University of Michigan Hospital or the Ann Arbor Veterans Administration Hospital. All patients suffered from paroxysmal, throbbing unilateral or bilateral head pain. These were associated with varying combinations of photophobia, anorexia, nausea, vomiting, visual symptoms, and focal neurologic symptoms. Furthermore, patients were analyzed for the presence of a family history of migraine and for characteristics of "common" or "classical" migraine. ${ }^{4}$ Where both occurred in the same patient, that person was classified as "classic." No patient with hemiplegic or ophthalmoplegic migraine was included.

\section{METHODS}

A heparinized blood sample was collected from each patient. Lymphocytes were prepared by the method of Boyum. ${ }^{5}$ A standard microlymphocytotoxicity test ${ }^{6}$ with a panel of 59 anti-sera was used to detect $10 \mathrm{HLA}$ specificities on the A locus and $14 \mathrm{HLA}$ specificities on the B locus. Histocompatibility antigens were determined in the 50 migraineurs and 80 normal, unrelated, Caucasian controls consisting of hospital employees and spouses of patients in other studies.

Statistical analysis consisted of comparison of the individual HLA antigens in patients with those in controls. The $p$ values were calculated using Fisher's exact test rather than the classical chi-square test since one or more entries were expected to be small. Each $p$ value was multiplied by the number of antigens studied to correct for the number of comparisons. ${ }^{7}$ All calculations were done at the Statistical Research Laboratory of the University of Michigan Computing Center using preconstructed programs.

\section{RESULTS}

Patient profile: Of the 50 patients sampled, 23 were men and 27 were women. A family history was identified in $31(62 \%)$. Twenty-one patients had classic migraine and 29 had common migraine. The frequency of a family history of migraine was the same in both subgroups. All migraine patients and controls were Caucasian.

HLA determinations (TABLE 1): The frequencies of the B8 $(p<0.02)$ and the B27 $(p<0.05)$ antigens were elevated in the migraine patients. After correcting for the number of comparisons, however, both associations fell below the level of significance. The presence or absence of a family history did not alter the increased frequencies of B8 and B27. However, AW24 was more common in those patients without a family history of migraine $(36.8 \%)$ than in 


\begin{tabular}{|c|c|c|c|c|c|c|}
\hline \multicolumn{7}{|c|}{ Table 1} \\
\hline Antigens & $\begin{array}{c}\text { Controls } \\
\mathrm{N}=80 \\
\%\end{array}$ & $\begin{array}{c}\text { Patients } \\
\mathrm{N}=50 \\
\%\end{array}$ & $\begin{array}{c}\text { Common } \\
\mathrm{N}=29 \\
\%\end{array}$ & $\begin{array}{c}\text { Classic } \\
\mathrm{N}=21 \\
\%\end{array}$ & $\begin{array}{c}\text { Positive } \\
\text { Family History } \\
\begin{array}{c}\mathrm{N}=31 \\
\%\end{array}\end{array}$ & $\begin{array}{c}\text { Negative } \\
\text { Family History } \\
\begin{array}{c}\mathrm{N}=19 \\
\%\end{array}\end{array}$ \\
\hline HLA-A1 & 33.8 & 44 & 41.4 & 47.6 & 45.2 & 42.1 \\
\hline HLA-A2 & 50.0 & 46 & 34.5 & $61.9^{4}$ & 54.8 & 31.6 \\
\hline HLA-A3 & 20.0 & 22 & 17.2 & 28.6 & 22.6 & 21.0 \\
\hline HLA-A9 & 11.3 & 8 & 10.3 & 4.8 & 9.7 & 5.3 \\
\hline HLA-A10 & 12.5 & 4 & 3.4 & 4.8 & 6.5 & - \\
\hline HLA-A11 & 10.0 & 10 & $17.2^{3}$ & - & 9.7 & 10.5 \\
\hline HLA-AW24 & 10.7 & 22 & 27.6 & 14.3 & 12.9 & $36.8^{5}$ \\
\hline HLA-A28 & 7.5 & 8 & 6.9 & 9.5 & 9.7 & 5.3 \\
\hline HLA-A29 & 10.3 & 8 & 10.3 & 4.8 & 3.2 & 15.8 \\
\hline HLA-AW32 & 10.7 & 4 & 6.9 & - & 6.5 & - \\
\hline HLA-B5 & 10.0 & 10 & 17.2 & - & 6.5 & 15.8 \\
\hline HLA-B7 & 22.5 & 18 & 13.8 & 23.8 & 16.1 & 21.0 \\
\hline HLA-B8 & 17.5 & $36^{1}$ & 34.5 & 38.1 & 35.5 & 36.8 \\
\hline HLA-B12 & 21.3 & 24 & 17.2 & 33.3 & 25.8 & 21.0 \\
\hline HLA-B13 & 6.3 & 2 & - & 4.8 & - & 5.3 \\
\hline HLA-B14 & 10.0 & 4 & 6.9 & - & 3.2 & 5.3 \\
\hline HLA-B15 & 10.0 & 4 & 3.4 & 4.8 & 6.5 & - \\
\hline HLA-BW16 & 3.6 & 14 & 10.3 & 19.0 & $12 . .9$ & 15.8 \\
\hline HLA-B17 & 8.8 & 6 & 10.3 & & 6.5 & 5.3 \\
\hline HLA-B18 & 4.3 & 2 & - & 4.8 & 3.2 & - \\
\hline HLA-BW22 & 4.2 & 4 & 3.4 & 4.8 & 3.2 & 5.3 \\
\hline HLA-B27 & 6.3 & $18^{2}$ & 20.7 & 14.3 & 16.1 & 21.0 \\
\hline HLA-BW35 & 26.3 & 16 & 13.8 & 19.0 & $12 . .9$ & 21.0 \\
\hline HLA-B40 & 5.0 & 10 & 6.9 & 14.3 & 12.9 & 5.3 \\
\hline${ }^{1} p=0.016$ & ${ }^{3} p=0.056$ & ${ }^{5} p=0.050$ & & & & \\
\hline${ }^{2} p=0.037$ & ${ }^{4} p=0.054$ & & & & & \\
\hline
\end{tabular}

Since family studies were not undertaken at this time, no haplotypes are available. However, A1 and B8 occurred together in 17 of the 50 patients (34\%). Due to the strong linkage disequilibrium between $A 1$ and $\mathrm{B} 8$, the expected frequency of $\mathrm{A} 1$ occurring with $\mathrm{B} 8$ is $17.2 \%$ within the Caucasian population. ${ }^{7}$ Eleven of these 17 patients had a family history of migraine.

A comparison of antigen frequencies in common and classic migraine demonstrated no significant correlations. B8 and B27 demonstrated an increased occurrence in both common and classic migraine. The patients carrying both $\mathrm{A} 1$ and B8 were equally divided between the common and classic subgroups. Therefore, the two groups of migraine patients could not be distinguished by these antigenic characteristics.

\section{DISCUSSION}

A family history of migraine is identified in $25-75 \%$ of patients depending upon the clinical subtype and the number of similarly affected parents. ${ }^{3}$ Wolff concluded that a multifactorial inheritance was probably operative in migraine. 8 No significant sex linkage or strict Mendelian inheritance has been convincingly identified.

Many chronic diseases are considered multifactorial genetic disorders, the disease expression requiring the interaction of multiple genes and complex environmental factors. The finding of an increased frequency of specific HLA antigens in various disorders suggests specific disease susceptibility, either because of genetic linkage ${ }^{9}$ or altered lymphocyte immune function. ${ }^{10}$

B8 and B27 were associated with migraine prior to correction for the number of alleles studies. B8 is frequently found with diseases where immune mechanisms are implicated, such as Sjögren's syndrome, chronic active hepatitis, and systemic lupus erythematosus. ${ }^{7,10}$ Furthermore, the prevalence of vascular headaches has been reported to be $25 \%$ in systemic lupus erythematosus, ${ }^{11}$ and $35 \%$ in mixed connective tissue disease. ${ }^{12}$

B27 is strongly associated with ankylosing spondylitis and Reiter's syndrome. ${ }^{7,10}$ There is no evidence that the prevalence of vascular headaches is increased in this group. However, we are currently surveying the prevalence of migraine in our population of more than 100 patients with B27-positive ankylosing spondylitis and Reiter's syndrome.

Our inability to demonstrate a statistically significant association of HLA-A and HLA-B locus antigens and migraine suggests that other loci or other factors may be operative in the pathophysiology. Kudrow ${ }^{13}$ also 
failed to demonstrate HLA association in 18 women with classic migraine concluding that the multifactorial inheritance most likely does not require the participation of the MHC. However, we feel that the suggestive association of migraine with B8 and B27 should be evaluated by study of a larger cohort of migraineurs and controls.

Acknowledgements: We thank the attending and house staffs of the Department of Neurology, University of Michigan Medical Center for referral of patients. We particularly wish to achnowledge the assistance of Drs. John D. Segall and Joel R. Saper. We also thank Mr. H. Lee Vahlsing for statistical analysis and Ms. Suzanne Lank and Ms. Edith L. Cole for secretarial assistance. The HLA typing was performed in the laboratory of Dr. Jane S. Schultz.

\section{REFERENCES}

1. Smeraldi E, Smeraldi RS, Cazzulo CL, el al: Immunogenetics of the Lennox-Gastaut syndrome: frequency of HLA antigens and haplotypes in patients with first degree relatives. Epilepsia 16:699-703, 1975.

2. Lord GDA, Duckworth JW, Charlesworth JA: Complement activation in migraine. Lancet 1:781-782, 1977.

3. Refsum S: Genetic aspects of migraine. In Vinken PJ, Bruyn GW (eds.) Handbook of Clinical Neurology. Amsterdam, North-Holland Publishing Company, 1968, vol. 5.

4. Friedman AP: Headache. In Baker AB, Baker LH (eds.): Clinical Neurology. Hagerstown, Harper and Row, 1976, vol. 2.

5. Boyum A: Separation of leukocytes from blood and bone marrow. Scand J Clin Lab Invest 21:Suppl 97, 1968.

6. Amos BD: In Ray JG, Hare DB, Pedersen PD, et al (eds.): NIAID Manual of Tissue Typing Techniques. Bethesda, Research Resources Branch (NIAID), 1976, pp 25-28.

7. Svejgaard A, Ryder LP: Associations between HLA and disease. In Dausset J, Svejgaard A (eds.): HLA and Disease. Copenhagen, Munksgaard, 1977.

8. Dalessio DJ: Wolff's Headache and Other Head Pain. New York, Oxford University Press, 1972.

9. Jackson JF, Currier RD, Terasaki PI, et al: Spinocerebellar ataxia and HLA linkage. $N$ Engl J Med 296:1138-1141, 1977.

10. Ritzmann SE: HLA patterns and disease associations. JAMA 236:2305-2309, 1976.

11. Atkinson RA, Appenzeller O: Headache in small vessel disease of the brain: A study of patients with systemic lupus erythematosis. Headache 15:198-201, 1975.

12. Bronshvag MM, Prystowsky SD, Traviesa DC: Vascular headaches in mixed connective tissue disease. Headache 18:154-160, 1978.

13. Kudrow L: HLA antigens in cluster headache and classical migraine. Headache 18:167-168, 1978. 